\title{
Selective Detection of Phosphopeptides in Complex Mixtures by Electrospray Liquid Chromatography / Mass Spectrometry
}

\author{
Michael J. Huddleston, Roland S. Annan, Mark F. Bean, \\ and Steven A. Carr \\ Department of Physical and Structural Chemistry, SmithKline Beecham, Pharmaceuticals, \\ King of Prussia, Pennsylvania, USA
}

\begin{abstract}
A mass spectrometry-based method that does not involve the use of radiolabeling was developed for selective detection of phosphopeptides in complex mixtures. Mixtures of phosphorylated and nonphosphorylated peptides at the low picomole level are analyzed by negative ion electrospray liquid chromatography/mass spectrometry using C-18 packed fused-silica columns ( $\leq 320-\mu \mathrm{m}$ i.d.). Peptides and phosphopeptides in the chromatographic eluant undergo collision-induced dissociation in the free-jet expansion region prior to the mass analyzing quadrupole. Using relatively high collisional excitation potentials, phosphopeptides containing phosphoserine, phosphothreonine, and phosphotyrosine fragment to yield diagnostic ions at $m / z 63$ and 79 corresponding to $\mathrm{PO}_{2}^{-}$and $\mathrm{PO}_{3}^{-}$, respectively. Chromatographic peaks containing phosphopeptides are indicated where these diagnostic ions maximize. The highest sensitivity for phosphopeptide detection is obtained using selected-ion monitoring for $m / z 63$ and 79. Full-scan mass spectra that exhibit the diagnostic phosphopeptide fragment ions, together with pseudomolecular ions, may be obtained by stepping the collisional excitation potential from a high value during the portion of each scan in which the low-mass-to-charge ratio diagnostic marker ions are being detected to a lower value while the upper mass-to-charge ratio range is being scanned. Good sensitivity for phosphopeptide detection was achieved using standard trifluoroacetic acid containing mobile phases for reversed-phase high-performance liquid chromatography. Data illustrating the selectivity and sensitivity of the approach are presented for mixtures of peptides and phosphopeptides containing the three commonly phosphorylated amino acids. (f Am SoC Mass Spectrom 1993, 4, 710-717)
\end{abstract}

$\mathrm{P}$ hosphorylation and dephosphorylation of Ser, Thr, and Tyr residues have a critical role in modulating the activity of a large number of regulatory proteins $[1-3]$. The addition of phosphate from a nucleoside triphosphate donor is catalyzed by a class of phosphotransferase enzymes known as protein kinases. Enzymes collectively referred to as protein phophatases catalyze the removal of specific phosphate groups. Evidence accumulated over the past decade has made it clear that these enzymes and their substrates form a complex, interconnected web that control most aspects of cell growth regulation [3].

Two major classes of protein kinases exist: phosphotransferases, with specificity toward the alcohol group of Ser and Thr, and those that transfer phosphate to Tyr [1-3]. Over 100 protein kinases have been identified, and, for many of these enzymes, the consensus sequences for recognition and protein phosphorylation

Address reprint requests to Steven A. Carr, Department of Physical and Structural Chemistry, SmithKline Beecham Pharmaceuticals, Box 1539, King of Prussia, PA 19406. have been identified $[4,5]$. These recognition paradigms consist of short linear sequences of amino acids surrounding the acceptor residue that have been identified by sequence analysis of the protein or peptide substrates for a particular kinase. However, in many cases the specificities of the phosphotransferase enzymes have only been deduced from sequence homology to protein kinases with experimentally determined specificities [2]. Because secondary and tertiary structural features of the substrate may often play significant roles in the recognition process, the presence of a consensus sequence is not sufficient evidence for phosphorylation. As underscored by Kennelly and Krebs [4], "Consensus sequence information functions best as a guide whose implications must be confirmed or refuted experimentally."

Numerous experimental strategies for determining the sites of phosphorylation during Edman sequence analysis of peptides have been devised. Such methods usually involve detection of inorganic $\left[{ }^{32} \mathrm{P}\right]$ phosphate (released into the wash or bound to the sample support) in the sequencer cycles [6-9] or detection of 
stable elimination products or derivatives such as $S$ ethylcysteine, which is formed from phosphoserine by $\beta$-elimination of the phosphate, followed by the addition of ethanethiol [10]. However, these methods are limited by the liability of the phosphoester bonds to Ser and Thr, the low recovery and high carryover of phosphotyrosine in the automated Edman chemistry, and the lack of specificity or incompleteness of reaction tor derivatives [6-11]. At present, the most reliable methods for determining the sequence and modification site of phosphopeptides utilize Edman degradation in combination with tandem mass spectrometry (MS/MS) [11-18].

Before phosphorylation sites can be determined, phosphopeptides must be produced and isolated from the phosphoprotein. This is usually accomplished by radiolabeling the intact protein with $\left[{ }^{32}\right.$ P]phosphate, cleaving it with a protease, such as trypsin, or chemically with cyanogen bromide, and then isolating the radiolabeled peptides following chromatographic separation [6-8]. Where the protein sequence is known, the molecular weight of the putative phosphopeptide obtained by mass spectrometry or liquid chromatography/mass spectrometry (LC/MS) analysis can be used to independently corroborate the presence of phosphate by the $80-\mathrm{Da}$ difference between the observed mass of the peptide and that calculated based on the sequence [12, 19-22]. A novel electrospray (ES) LC/MS procedure has been developed by Covey et al. [23] that employs neutral-loss scanning to identify phosphopeptides in mixtures on the basis of their tendency to lose neutral phosphoric acid from the doubly charged precursor (i.e., a loss of $98 \mathrm{Da} / z=98 / 2=49$ ). Such losses are favored for phosphoserine and phosphothreonine, which can readily undergo $\beta$-elimination of the side chain [12]. Unfortunately, different mass-to-charge ratio values must be monitored for the same neutral loss, depending on the charge states of the precursors: this can only be practically accomplished in separate LC/MS/MS experiments for each charge state [24]. Moreover, it is unlikely that phosphotyrosine will undergo a neutral loss of phosphoric acid because such a loss would require that a bond to the aromatic ring be broken.

We developed a mass spectrometry-based strategy for selective identification of peptides containing phosphate linked to Ser, Thr, and Tyr without the need for radiolabeling. The method involves the generation and detection of phosphate-specific fragment ions during negative ion LC/ESMS analysis of protein digests. The present work is an outgrowth of our earlier studies on methods for selective glycopeptide detection [24, 25]. Once phosphopeptides have been identified, Edman degradation and ESMS/MS may be used to provide the sequence and location of the phosphorylated amino acid [16-18]. Here we illustrate the selectivity and sensitivity of the approach using a mixture of peptides and phosphopeptides containing the three commonly phosphorylated amino acids.

\section{Experimental}

Phosphopeptides and their norphosphory lated antalugs (Table 1) were obtained from the Protein and Carbohydrate Structure Facility, University of Michigan Medical School (Ann Arbor, MI). Peptides 7-11 (Table 2) were obtained as a mixture (Peptide Retention Standard, S1-S5) from Pierce (Rockford, IL). All other peptides (Table 2) were obtained from Peninsula Laboratories (Belmont, $\mathrm{CA}$ ) or Bachem Bioscience, Inc. (Philadelphia, PA). All peptides were used without further desalting or purification. Peptides were infused directly into the mass spectrometer at $200 \mathrm{pmol} / \mu \mathrm{L}$ in water/acetonitrile $68: 32(\mathrm{v} / \mathrm{v})$ containing $0.08 \%$ trifluoroacetic acid (IFA) at a flow rate of $4 \mu \mathrm{L} / \mathrm{min}$ by means of a model 22 Harvard Apparatus Syringe pump (South Natick, MA).

A mixture of $50 \mathrm{pmol}$ of each of the six model compounds was used for the initial LC/ESMS analyses using packed capillary columns. Gradient high-performance liquid chromatography (HPLC) was carried out using an Applied Biosystems 140B Microgradient system (Foster City, CA) with dual syringe pumps, a $250-\mu \mathrm{L}$ dynamic mixer, and a Rheodyne model 8125 injector with a $20-\mu \mathrm{L}$ replaceable sample loop. The HPLC column was an LC Packings (San Francisco, CA) Fusica capillary column $(320 \mu \mathrm{m} \times 15 \mathrm{~cm})$ custom packed with $5-\mu \mathrm{m}, 300-\AA$ pore size, $C-18$ packing from Vydac (The Separations Group, Hesperia, CA). Absorbance was monitored at $215 \mathrm{~nm}$ using an Applied Biosystems model $785 \mathrm{~A}$ programmable absorbance detector. The flow cell of the detector was replaced with an LC Packings $U-Z$ View capillary flow cell with a 35-nL internal volume and $8-\mathrm{mm}$ path length. The flow of the mobile phase was reduced from approximately $100 \mu \mathrm{L} / \mathrm{min}$ at the pump down to $4-5 \mu \mathrm{L} / \mathrm{min}$ leading to the injector and column utilizing a solvent split at a low dead-volume Valco tee with a length of fused-silica restrictor on the waste leg. The capillary column fits directly into the injector, and a fused-silica extension tube connects the column to the UV detector. A second length of $50-\mu \mathrm{m}$ i.d. fused silica leads from the UV detector and is threaded directly to the tip of the ion-spray needle. The mobile phases used for radiant elution consisted of (A) $0.1 \%(\mathrm{v} / \mathrm{v})$ TFA and (B) acetonitrile/water 90:10 $(\mathrm{v} / \mathrm{v})$ containing $0.1 \%$ TFA.

Table 1. Phosphorylated peptide models and their corresponding nonphosphorylated analogs

\begin{tabular}{lc}
\hline \multicolumn{1}{c}{ Sequence } & $M_{\mathrm{r}}^{2}$ (monoisotopic) \\
\hline \hline $\mathrm{KRT}\left(\mathrm{PO}_{3} \mathrm{H}_{2}\right.$ )IRR & 908.5 \\
$2 \mathrm{KRTIRR}$ & 828.5 \\
$3 \mathrm{KRPS}\left(\mathrm{PO}_{3} \mathrm{H}_{2}\right.$ IORHGSKY & 1422.7 \\
$4 \mathrm{KRPSORHGSKY}$ & 1342.7 \\
5.Ac-RRLIEDAEY(PO $\mathrm{H}_{2}$ IAARG-NH $_{2}$ & 1639.8 \\
6. AC-RRLIEDAEYAARG-NH & 1559.8 \\
\hline
\end{tabular}

${ }^{2} M_{f}$. relative molecular mass. 
Table 2. Components of a mixture containing peptides and phosphopeptides

\begin{tabular}{|c|c|}
\hline Sequence & $\frac{M_{r}^{\mathrm{a}}}{\text { (monoisotopict }}$ \\
\hline 1 TYSK & 497.2 \\
\hline $2 \mathrm{LGG}$ & 245.1 \\
\hline $3 \mathrm{KRT}\left(\mathrm{PO}_{3} \mathrm{H}_{2}\right)$ IRR & 908.5 \\
\hline $4 \mathrm{KRPS}\left(\mathrm{PO}_{3} \mathrm{H}_{2}\right) \mathrm{ORHGSKY}$ & 1422.7 \\
\hline 5 KRTIRR & 828.5 \\
\hline 6 KRPSORHGSKY & 1342.7 \\
\hline 7 RGAGGLGLGK-NH ${ }_{2}$ & 883.5 \\
\hline 8 AC-RGGGGLGLGK-NH & 911.5 \\
\hline 9 Ac-RGAGGLGLGK-NH ${ }_{2}$ & 925.5 \\
\hline $10 \mathrm{Ac}-\mathrm{RGVGGLGLGK-NH_{2 }}$ & 953.6 \\
\hline 11 Ac-RGVVGLGLGK-MH ${ }_{2}$ & 995.6 \\
\hline 12 ISRPPGFSPFR & 1259.7 \\
\hline $13 \mathrm{MLF}$ & 409.2 \\
\hline $14 \mathrm{AC}$-RRLIEDAEY $\left(\mathrm{PO}_{3} \mathrm{H}_{2}\right.$ )AARG-NH & 1639.8 \\
\hline 15 Ac-RRLIEDAEYAARG-NH ${ }_{2}$ & 1559.8 \\
\hline 16 DRVYIHPFHLLVYS & 1757.9 \\
\hline
\end{tabular}

M, relative molecular mass

The gradient conditions were as follows: $5 \%$ B (hold 5 min) to $50 \%$ B linearly in $30 \mathrm{~min}$; then linearly to $100 \%$ $B$ in 5 min with no delays. Separations using $2.1-\mathrm{mm}$ columns wete carried out using a Beckman System Gold (San Ramon, CA) equipped with a model 126 programmable solvent module and model 166 variable-wavelength detector with microflow cell. An AST286 PC was used to control the system and to store and manipulate data via the System Gold software. The standard mixer on the 126 solvent module was replaced with a Lee Visco-Jet Micro-Mixer (Westbrook, CT) with a $250-\mu \mathrm{L}$ internal volume. Reversed-phaseHPLC separation was done on a fully end-capped C-18 column from Vydac $(25-\mathrm{cm} \times 2.1-\mathrm{mm}$ i.d, with $5-\mu \mathrm{m}$ particles) with a Brownlee RP-300 guard column ( $30 \times$ $2.1 \mathrm{~mm}$ i.d., $7-\mu \mathrm{m}$ particle size) using linear gradient elution (as above) at $200 \mu \mathrm{L} / \mathrm{min}$. A flow of $5 \mu \mathrm{L} / \mathrm{min}$ from the column was diverted to the mass spectrometer, as described above.

ES mass spectra were recorded on a Perkin-Elmer Sciex API-III triple quadrupole mass spectrometer (Thornhill, Ontario, Canada) fitted with an articulated, pneumatically assisted nebulization probe and an atmospheric pressure ionization source. The tuning and calibration solution consisted of a mixture of polypropylene glycol (PPG) 424, 1000, and $2000(3 \times$ $10^{-5} \mathrm{M}, 1 \times 10^{-4} \mathrm{M}$, and $2 \times 10^{-4} \mathrm{M}$, respectively) in 50:50:0.1 water/methanol/formic acid $(\mathrm{v} / \mathrm{v} / \mathrm{v}), 1 \mathrm{mM}$ $\mathrm{NH}_{4} \mathrm{OAc}$. The range $\mathrm{m} / z \quad 10-2400$ was calibrated in the negative ion mode by multiple-ion monitoring of the isotope clusters of five PPG ion signals and the TFA anion $(\mathrm{m} / \mathrm{z}$ 113). Mass-to-charge ratio assignments in the figures are the measured peak tops and are closer either to the monoisotopic or to the average mass-to-charge ratio, depending on the charge state and the isotopic distribution. ES and LC/ES mass spectra were recorded at instrument conditions sufficient to resolve the isomers of the PPG $/ \mathrm{HCO}_{2}^{-}$singly charged anion at $m / z 992$ (55\% valley definition). The ion-spray needle voltage was operated at $-3.7 \mathrm{kV}$, with the interface plate at $-700 \mathrm{~V}$. The nebulization gas consisted of compressed air purified by a Balston 75-85 Zero Grade Air Generator (Lexington, MA) at 35-40 psi flowing at $0.8 \mathrm{~L} / \mathrm{min}$. A curtain of bottled nitrogen as $(99.999 \%)$ was used at a flow rate of 0.8 $\mathrm{L} / \mathrm{min}$. Our experience shows $\mathrm{Q} 1$ transmitting lowmass ions more efficiently than $Q 3$ in conventional scan modes, so we used $\mathrm{Q} 1$ exclusively in these experiments.

For infusions of single compounds, Q1 was scanned over a range of $m / z 50-1800$ at $6 \mathrm{~s} / \mathrm{scan}$ in $0.25-\mathrm{m} / \mathrm{z}$ steps; mass spectra were recorded at orifice (OR) potentials of $-65,-115$, or $-350 \mathrm{~V}$. The observation that the intensity of the low-mass, phosphopeptide marker ions was still increasing at the highest allowable $O R$ setting of $-250 \mathrm{~V}$ suggested the need for even higher OR voltages. Furthermore, because we wished to be able to step the OR voltage during the scan, it was necessary that the OR power supply be under computer control. By disconnecting the standard OR power supply and connecting the computer-controlled interface power supply to the OR and an external power supply (Bertan, Hicksville, NY) to the interface plate, we were able to achieve OR values of $\pm 700 \mathrm{~V}$.

During LC-ESMS using single-ion monitoring (SIM), the Q1 mass analyzer was scanned to monitor $\mathrm{m} / \mathrm{z}$ 62.87-63.12, $m / z \quad 78.87-79.12$, and $m / z$ 96.87-97.12 using $0.05-m / z$ steps, a dwell time of $330 \mathrm{~ms} / \mathrm{step}$, and a total scan time of $0.57 \mathrm{~s}$. For a related SIM experiment, the $Q 1$ mass analyzer was set to monitor only the peak tops $(m / z 63.0,79.0$, and 97.0) with a dwell time of $125 \mathrm{~ms}$ and a total scan time of $0.56 \mathrm{~s}$ (data not shown). The OR voltage was set to $-350 \mathrm{~V}$ for both SIM experiments, and no significant differences were observed between the two approaches.

For full-scan LC/ESMS, the quadrupole was scanned discontinuosly over the ranges $m / z$ 59-99 and $m / z \quad 400-2000$ in $0.25-m / z$ steps and a total scan time of $6 \mathrm{~s}$. The OR voltage was set to $-350 \mathrm{~V}$ during acquisition of the range $m / z$ 59-99 and then stepped to $-115 \mathrm{~V}$ and held constant from $m / z 400$ to 2000 (see, later, dotted line in Figure 4a).

\section{Results and Discussion}

An objective of this study was to identify marker ions that could be used to locate phosphopeptide-containing fractions during LC-ESMS of an enzymatically digested, phosphorylated protein. Using such a method, fractions identified as phosphopeptide containing could then be collected and further analyzed by other techniques (e.g., positive ion mass spectrometry, MS/MS, amino acid analysis, Edman degradation) to corroborate the presence of phosphate and to identify the 
precise phosphorylation site(s). To accomplish this we studied three phosphopeptide models (Table 1), each of which contained either Ser-, Thr-, or Tyr-linked phosphate, and three homologous peptides lacking phosphate, which acted as model controls.

Positive and negative ion ES mass spectra of the phosphopeptides were recorded over a wide range of OR potentials (from 65 to $250 \mathrm{~V}$ in positive ion; from -65 to $-250 \mathrm{~V}$ in negative ion). On the Sciex quadrupole mass spectrometer, the $\mathrm{OR}$ voltage is the source declustering potential, and this voltage is also used to control the degree of collision-induced dissociation (CID) occurring in the high-pressure region between the OR and Q1. No characteristic low massto-charge ratio fragment ions were observed in the positive ion data for the phosphopeptides over the range of $O R$ values studied (date now shown), however, fragments formed by loss of $\mathrm{H}_{3} \mathrm{PO}_{4}$ from the pseudomolecular ions could be observed for the peptides phosphorylated on Ser or Thr in both the negative and positive ion spectra. The loss of phosphoric acid was more pronounced in the positive ion data and appeared at lower collisional excitation potentials than in the negative ion data. Interestingly, strong losses of $17 \mathrm{Da}\left(\mathrm{NH}_{3}\right), 18 \mathrm{Da}\left(\mathrm{H}_{2} \mathrm{O}\right), 80 \mathrm{Da}\left(\mathrm{HPO}_{3}\right)$, and $98 \mathrm{Da}\left(\mathrm{H}_{3} \mathrm{PO}_{4}\right)$ were observed at relatively high
OR values in both the positive and negative ion data for the phosphotyrosine-containing model peptide (compound 5, Table 1). The product ion spectrum of the $[\mathrm{M}+2 \mathrm{H}]^{2+}$ of this peptide in positive ion also exhibited intense ions corresponding to the same four losses (data not shown), however, it is most likely that the 98-Da loss is due to the combined loss of $\mathrm{H}_{2} \mathrm{O}$ (from a residue other than phosphotyrosine) and $\mathrm{HPO}_{3}$, rather than the direct loss of $\mathrm{H}_{3} \mathrm{PO}_{4}$ from phosphotyrosine. This conclusion is consistent with literature reports on the mass spectrometry and MS/MS of phosphotyrosine-containing peptides $[12,16,18]$. The apparent absence of phosphoric acid loss from phosphotyrosine (with the exception of nominally equivalent losses, as noted above) and the fact that the charge state of the parent ion must be known in advance limit the utility of neutral loss scanning as a general method for phosphopeptide detection (or glycopeptide detection; see ref, 24) in LC/ESMS. Furthermore, the biological importance of Tyr phosphorylation militates for a more universal method of detection.

At sufficiently high absolute OR potentials (collision energies), the negative ion ES mass spectra for all three varieties of phosphate linkage showed two unique phosphopeptide fragment ions: $m / z 79\left(\mathrm{PO}_{3}^{-}\right)$and $m / z 63\left(\mathrm{PO}_{2}^{-}\right)$(see Figure 1c). Although $m / z 97$
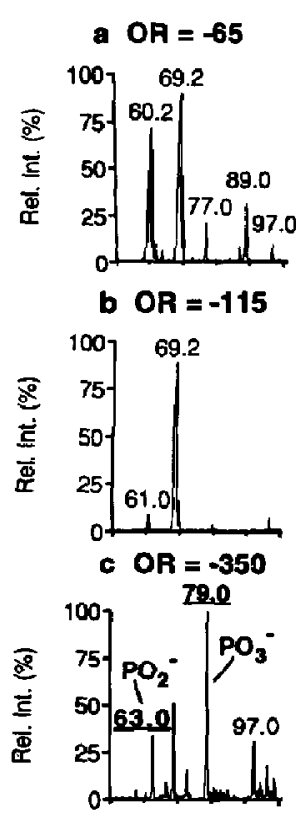
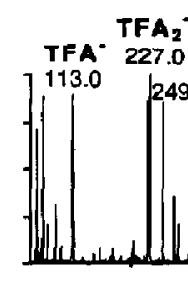

$\mathrm{TFA}_{2}$
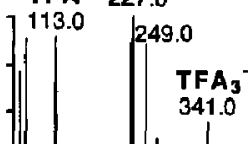

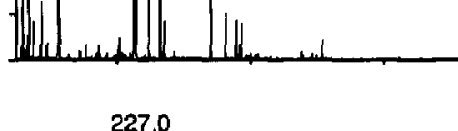

$\stackrel{\left(\mathrm{PO}_{3} \mathrm{H}_{2}\right)}{K R P S Q R H G S K Y}$
KR Q

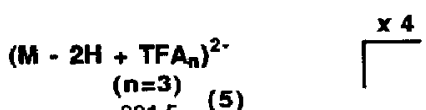

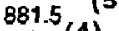
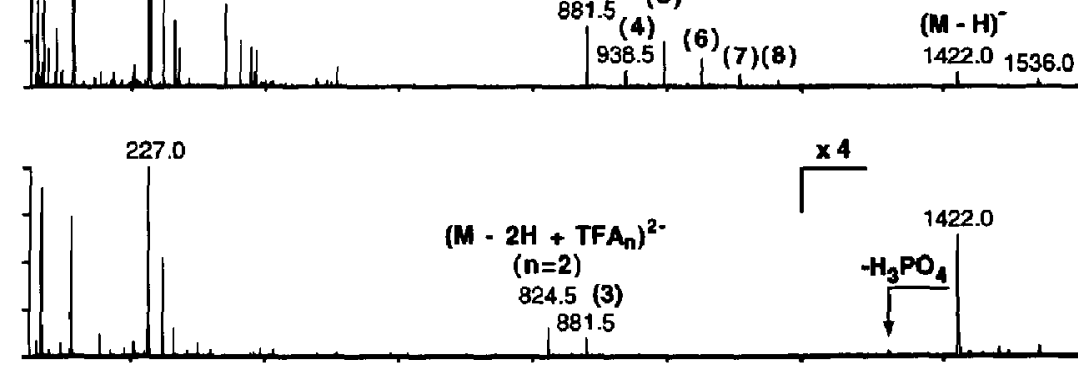

$4,634,118$

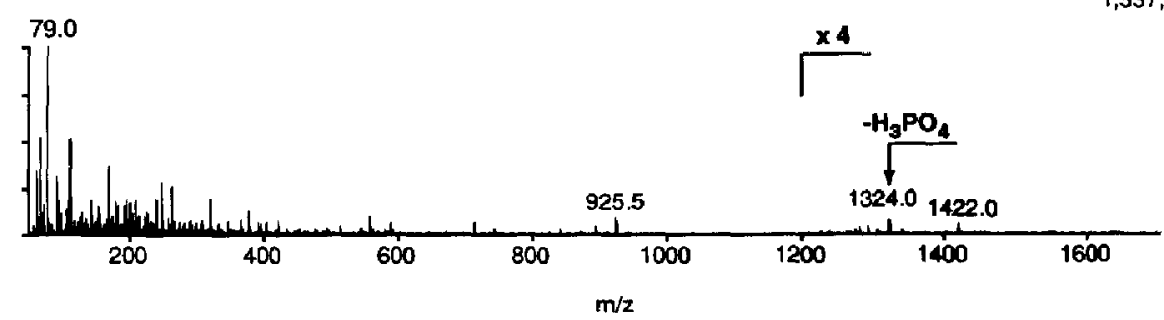

$1,537,647$

Figure 1. Effect of orifice (OR) voltage on negative ion ES mass spectra of the phosphoserinecontaining peptide (KRPS $\left(\mathrm{PO}_{3} \mathrm{H}_{2}\right)$ QRHGSKY). Sum of five scans; 400 pmol consumed. The region $m / z$ 50-100 showr in the expansion on the left is on the same vertical scale as the full spectrum illustrated on the right. Rel. Int., relative intensity. 
$\left(\mathrm{H}_{2} \mathrm{PO}_{4}^{-}\right)$can derive from two of the phosphorylated peptides, the observation of $m / z 97$ is not diagnostic for phosphorylated peptides because anions of this mass-to-charge ratio can derive from other sources, such as sulfated peptides or TFA $\left(\mathrm{C}_{2} \mathrm{~F}_{3} \mathrm{O}^{-}\right)$. Indeed, a reconstructed ion trace for $m / z 97$ in the LC-ESMS data resulted in marked signal intensity increases (chromatographic peaks) during elution of phosphorylated and nonphosphorylated peptides alike, presumably due to CID of the abundant [M + TFA $\left.{ }_{n}\right]^{-}$adduct species (see below). Our strategy was to convert, by means of higher in-source collision energies, any phosphate-derived signal at $m / z 97$, which is nonspecific, into $m / z 79\left(\mathrm{PO}_{3}^{-}\right)$and $m / z 63\left(\mathrm{PO}_{2}^{-}\right)$, which are highly specific. The diagnostic value of $m / z \quad 79$ for phosphopeptide detection was substantiated in the case of the phosphotyrosine peptide by acquiring a CID product ion spectrum of the $[\mathrm{M}-2 \mathrm{H}]^{2-}$ ion at $\mathrm{m} / \mathrm{z}$ 813.2 using a collision cell (Q2) with argon target gas (data not shown). Thus, the high specificity of the two marker ions makes in-source CID, negative ion LC/ESMS a useful and universai method for locating phosphopeptide-containing peaks during HPLC separation.

Negative ion ESMS was optimized for detection of the phosphopeptide-specific marker ions using the phosphoserine-containing peptide, which gave the weakest response of the three types of phosphorylated peptides. At $O R$ values ranging from -65 to $-115 \mathrm{~V}$ (Figure $1 \mathrm{a}$ and $\mathrm{b}$ ), we observed $[\mathrm{M}-\mathrm{H}]^{-},[\mathrm{M}-\mathrm{H}+$ TFA $]^{-}$, and $\left[\mathrm{M}-2 \mathrm{H}+(\mathrm{TFA})_{n}\right]^{2-}$ ions, where $n=$ 1-8, depending on the voltage and the peptide composition. TFA adducts to the molecular ion were greatly diminished at $-115 \mathrm{~V}$ compared with the standard $-65 \mathrm{~V}$ setting. Minimization of adducts simplifies the spectral data, facilitates molecular weight measurements when dealing with mixtures, and improves the intensity of individual signals (e.g., compare the [M -
$\mathrm{H}^{-}$appearing at $m / z 1422$ in Figure $1 \mathrm{a}$ and b). On the other hand, the spacing between the TFA adducts can be used to determine the charge state if a molecular weight-related ion; observation of peaks $57 \mathrm{~m} / \mathrm{z}$ apart implies doubly charged ions $(114 / 2=57$ ) (see Figure 1a). In 'IFA-containing mobile phases the marker ions appearing at $m / z 63.0$ and 79.0 maximized at $O R$ settings of approximately $-350 \mathrm{~V}$ (which is $100 \mathrm{~V}$ beyond the $\pm 250-V$ range of the standard power supply for the instrument; see Experimental for details of the conversion of the power supply setups). The abundance of $m / z 63.0$ increased approximately tenfold and that of $\mathrm{m} / z \quad 79.0$ approximately twofold by increasing the OR voltage from -250 to $-350 \mathrm{~V}$. TFAderived fragment ions at $m / z \quad 69\left(\mathrm{CF}_{3}^{-}\right)$and 97 $\left(\mathrm{C}_{2} \mathrm{~F}_{3} \mathrm{O}^{-}\right)$were observed at all $\mathrm{OR}$ values. At higher $O R$ voltages (greater than $-200 \mathrm{~V}$ ), significant $[\mathrm{M}-\mathrm{H}$ $\left.-\mathrm{H}_{3} \mathrm{PO}_{4}\right]^{-}$or $\left[\mathrm{M}-\mathrm{H}-\mathrm{H}_{2} \mathrm{O}-\mathrm{HPO}_{3}\right]^{-}$fragment ions and peptide backbone fragment ions were also observed for the three model phosphopeptides (e.g.r see Figure 1c). In non-TFA-containing mobile phases (e.g., aqueous/organic mixtures containing $0.2 \%$ formic acid or $0.2 \% \mathrm{NH}_{3}$ ), $\mathrm{m} / z \quad 63$ and 79 were observed to maximize at an OR voltage of approximately $-200 \mathrm{~V}$. This suggests that postcolumn addition of modifiers such as formic acid may permit lower OR settings to be employed during negative ion LC/ESMS for marker ion generation with high sensitivity.

The optimized orifice setting of $-350 \mathrm{~V}$ was then applied to the LC/ESMS analysis of a mixture of the six model peptides shown in Table 1 using simultaneous UV detection and SIM. All six standards can be seen in the UV trace (Figure 2a), whereas the three phosphopeptides were selectively detected by the summed ion traces for the phosphate marker ions $\mathrm{m} / \mathrm{z}$ 63 and 79 (Figure 2b). The obvious benefits of the SIM approach to LC/ESMS analyses include highly specific detection of phosphopeptides, much enhanced signal-
Figure 2. Comparison of the simultaneously acquired (a) UV (215 nm) and (b) negative ion single-ion monitoring (SIM) mass spectrometry $(m / z 63$ and 79) traces from an LC separation of a mixture of 50 prrol of each of the six peptides shown in Table 1. Rel. Int., relative intensity.

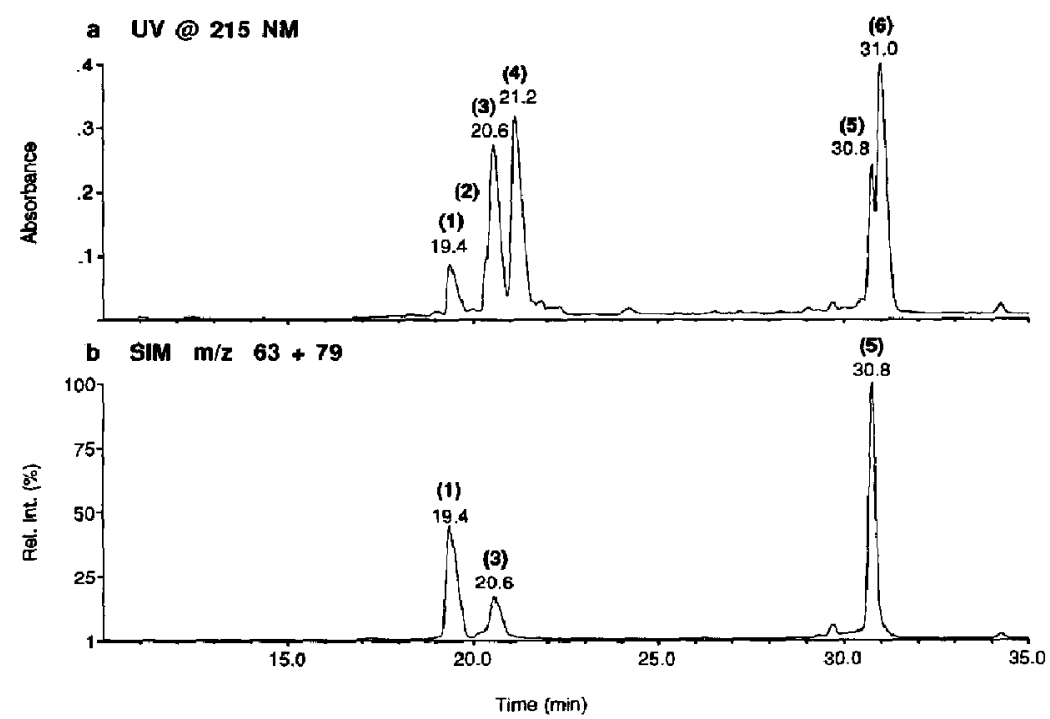


to-noise ratio, and consequent lower limit of detection, and improved chromatographic peak definition, which results from faster data acquisition (e.g., $0.5 \mathrm{~s} / \mathrm{scan}$ ). The disadvantage of the technique is the absence of any molecular weight information; further analysis of the collected fractions of LC/ESMS in a full-scan mode is necessary to obtain molecular weights.

We also investigated techniques for selective detection of phosphorylated peptides that preserved molecular weight information in the LC/ESMS data. The OR voltage setting, which controls the CID potential, must be adjusted so as to maximize within each spectrum the characteristic fragment ion signals and to minimize parent ion fragmentation. These contradictory requirements are met by scanning or stepping the $O R$ voltage during full-scan acquisition in a manner analogous to that previously described for selective detection of glycopeptides in LC/ESMS [24, 25]. We have previously referred to this technique of stepping or ramping the CID potential as collisional excitation scanning (24). The OR setting of $-115 \mathrm{~V}$, which is sufficient to effectively reduce TFA adducted to the parent ions, and the $-350-V$ OR setting, used for generation of phosphopeptide marker ions, were combined into a single scan by computer-controlled stepping of the OR voltage (see Experimental). Because the TFA-containing mobile phase produces significant background ions even at an orifice setting of $-350 \mathrm{~V}$ (Figure 1c), the mass-to-charge ratio range between $m / z 100$ and 400 was omitted from the full-scan mode LC/ESMS acquisition. The resulting spectra would contain diagnostic fragments, if present, in the low mass-to-charge ratio region and molecular weight-related ions for all pep- tides, phosphorylated or not, in the higher mass-tocharge ratio region.

We applied this full-scan, stepped collision energy method to the same mixture of peptides as was used for the SIM experiments (Table 1). The resulting total ion chromatogram (TIC) (Figure 3a) is qualitatively similar to the UV trace in Figure 2a. As expected, these traces do not correspond quantitatively because the UV detector and mass spectrometer are responding to different characteristics of the peptides [26]. Although both the UV and TIC traces provide relatively nonspecific detection of peptides and phosphopeptides, the reconstructed ion chromatogram for $m / z 79$ (Figure $3 b)$ was nearly identical to the summed ion trace of $m / z 63$ and 79 from the SIM experiment (Figure 2b), and both were specific for phosphopeptides. The molecular weights of the six peptides (Table 1) were indicated by significant, singly charged, deprotonated molecular ions together with their less intense TFA-adduct satellite peaks (see Figure 4 for the three spectra of the three phosphopeptides). We also observed doubly charged molecular ions in the form of a series of TFA adducts with the $[\mathrm{M}-2 \mathrm{H}]^{2-}$ not always present. Although the phosphoserine peptide gave the poorest response, it was clearly identified as a phosphorylated peptide, and the molecular weight was determined in the LC/MS data at the 50-pmol level. Additional improvements in the sensitivity for detection of the phosphopeptide marker ions during full-scan acquisition could be gained by using variants of the scan method described. For example, a scan in which $m / z 63$ and 79 are selectively monitored at high OR for long dwell times (e.g., $100 \mathrm{~ms}$ ) prior to the "full-scan"s portion of

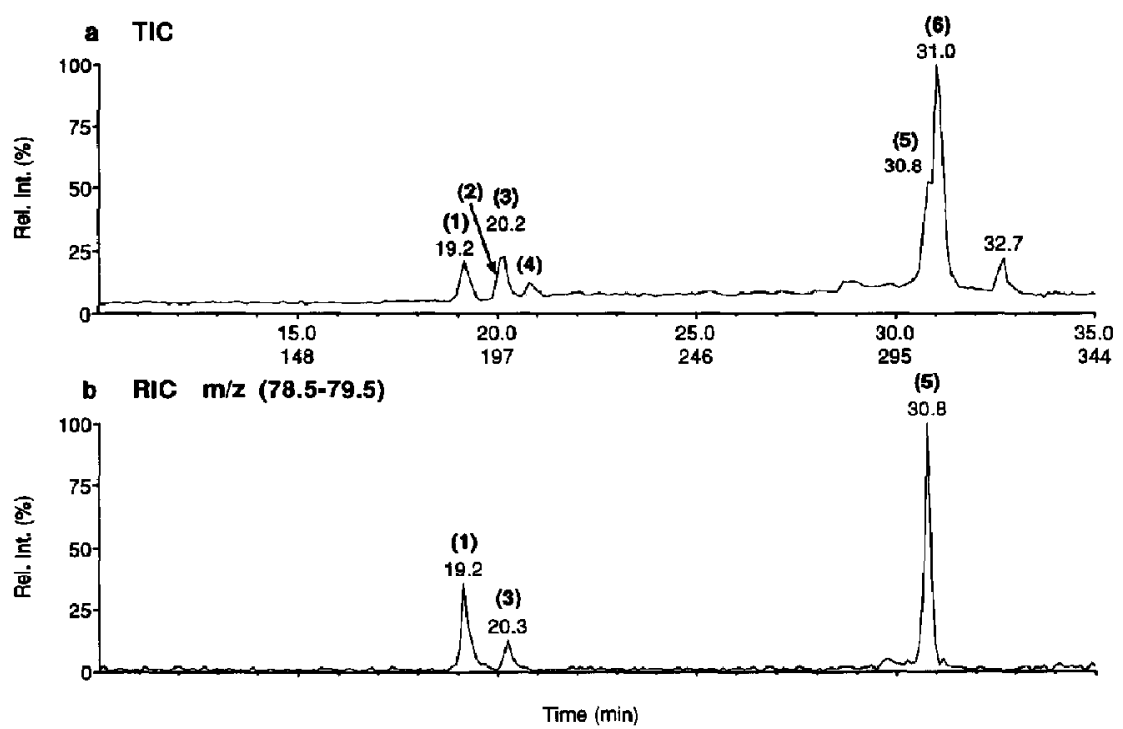

Figure 3. Negative ion, stepped collisional excitation, scanning LC/ES mass spectra using the same peptide mixture as in Figure 2. (a) Total ion chromatogram (TTC); (b) reconstructed-ion chromatogram (RIC) for $m / z 79\left(\mathrm{PO}_{3}^{-}\right)$. 


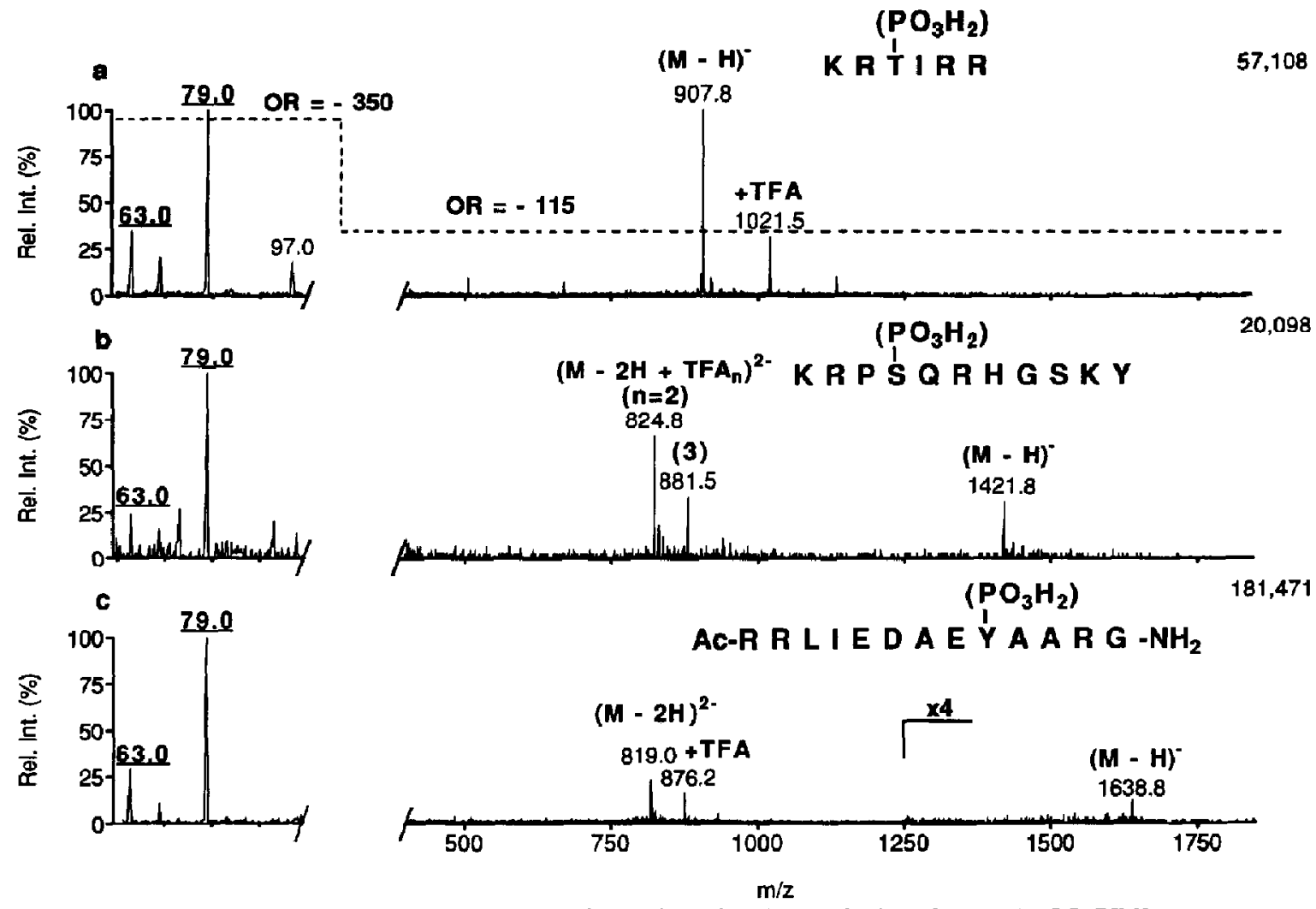

Figure 4. Negative ion ES mass spectra for the three phosphopeptides from the scanning LC/ESMS experiment shown in Figure 3. The break in the $x$ axis between $m / z 99$ and 400 indicates the scan discontinuity (see Experimental for details). (a) Peak 1; (b) peak 3; (c) peak 5. OR, orifice voltage; Rel. Int., Relative intensity.

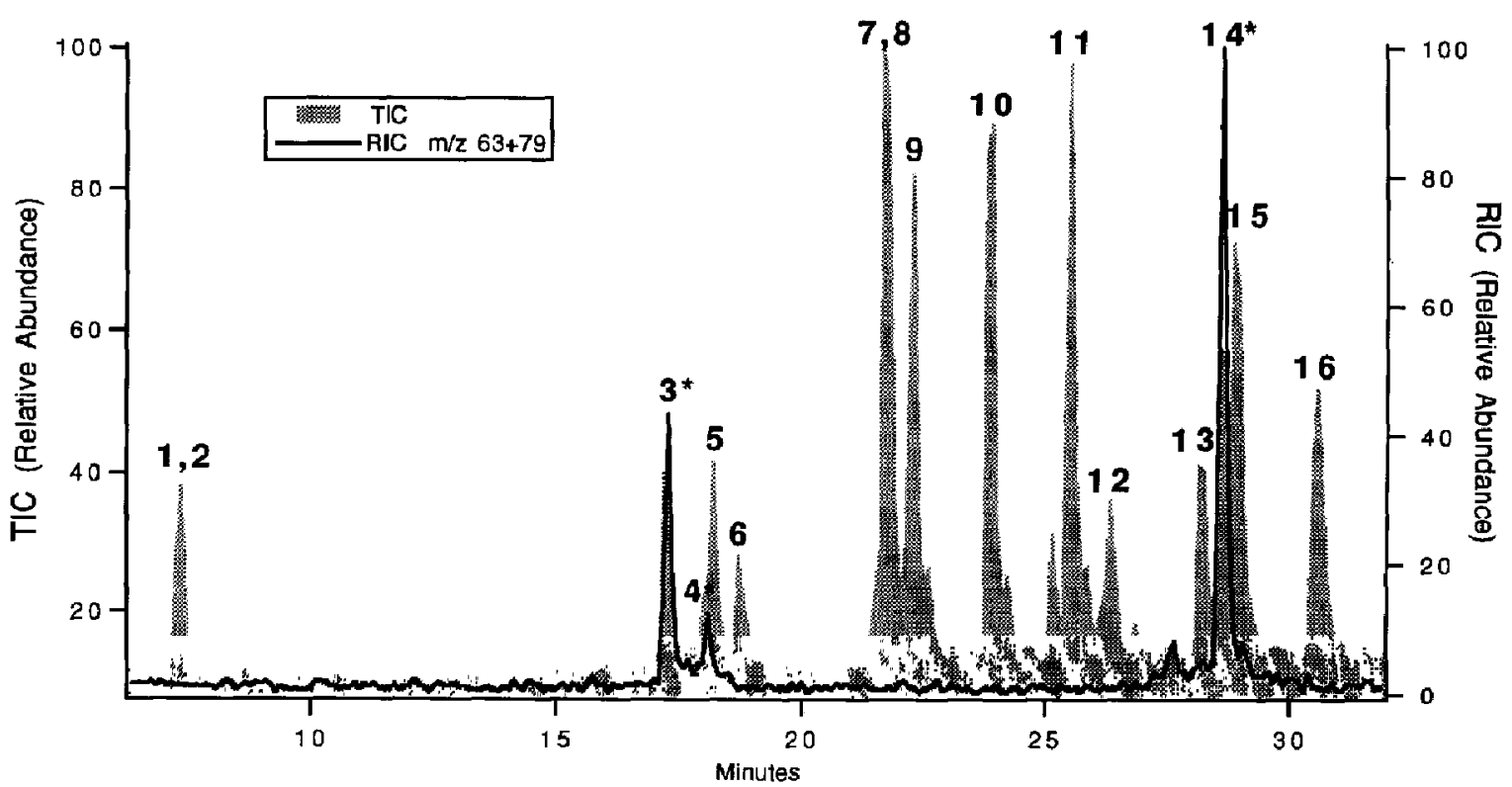

Figure 5. Negative ion, stepped collisonal excitation, scanning LC/ES mass spectra of the peptide mixture shown in Table 2 . TIC, total ion chromatogram; RIC, reconstructed ion chromatogram for $m / z 63\left(\mathrm{PO}_{2}^{-}\right)$and $79\left(\mathrm{PO}_{3}^{-}\right)$; phosphopeptides are denoted by ${ }^{*}$. 
each spectrum (3-5s) would improve sensitivity without significantly lengthening the duration of each scan. I his scan method is presently not supported by the software on the Sciex API-III.

The potential utility of the stepped collision energy method for selective detection of phosphopeptides in complex mixtures is illustrated in Figure 5 for a mixture of 16 peptides (Table 2), only three of which are phophorylated. No false positives were detected; only the phosphopeptides produced response at $\mathrm{m} / \mathrm{z} 63$ and 79. The peptides in this more complex mixture contain 17 of the 20 commonly occurring amino acids; only Asn, Sys, and Trp are not represented. However, in other studies, peptides containing Asn and Trp also did not give rise to false positives (Annan and Carr, unpublished observations). Peptides containing Cys (and alkylated forms thereof) have not yet been studied.

The techniques investigated in this report make it possible to selectively detect phosphopeptides in a mixture. Sensitivity was carefully evaluated, although the spectral quality indicates that we are not at the sensitivity limit for either full-scan or SIM detection. On the basis of the observed ion count rates, we estimate that it should be possible to obtain useful data at the 1-5-pmol level in the SIM-LC/MS mode. The relative response of phosphorylated and nonphosphorylated peptides in the full-scan negative ion mode has not yet been studied in detail, however, within each pair of peptides, the relative responses of the molecular weight-related ions for equimolar amounts of the phosphorylated versus the nonphosphorylated forms were within a factor of 3 . Further studies will be required to determine whether the selected ion current traces for the molecular weight-related ions can be used to provide a rough estimate of the extent of phosphorylation at a given site. More quantitative estimates may be obtained from the UV trace, in instances where the phosphorylated and nonphoshorylated peptide peaks are well resolved, or by N-terminal sequencing of the peptides in isolated fractions. Work is now in progress to use negative ion LC/ESMS with collision energy scanning to identify phosphopeptides from enzymatically digested phosphorylated proteins. We anticipate that negative ion LC/ESMS will provide useful, complementary data to those normally obtained in the positive-ion mode for protein digests, and that together these data sets could be used to improve the overall mapping of the sequence.

\section{Acknowledgments}

We thank Dr. Bruce Thompson, PE-SCIEX, for helpful discussions.

\section{References}

1. Krebs, E. G. Biachem. Soc. Trarls. 1985, 13, 813-820.

2. Hunter. T. Methods Enzymol. 1991, 200, 3-37.

3. Cohen, P. Trends Biochem. Sci. 1992, 17, 408-413.

4. Kennelly, P. J.; Krebs, E. G. I. Biol. Chem. 1991, 266, 15555-15558.

5. Kemp, B. E.; Pearson, R, B. Trends Biochem. Sci. 1990, 15, 342346.

6. Boyle, W. J.; van der Geer, P.; Hunter, T. Methods Enzymol. 1991, 201, 110-152.

7. Luo, K.; Hurley, T. R.; Sefton, B. M. Methods Enzymol. 1991, 201, 149-152.

8. Wettenhall, R. E. H.; Aebersold, R. H.; Hood, L. E. Methods Frizymol. 1991, 201, 186-199.

9. Roach, P. J.; Wang, Y. Methods Enzymol. 1991, 201, 200-224.

10. Meyer, H. E.; Hoffmann-Posorske, E.; Heilmeyer, L. M. G. Jr. Methods Enymol. 1991, 201, 169-185.

11. Cohen, P.; Gibson, B. W.; Holmes, C. F. B. Methods Enzymol. 1991, 201, 153-168.

12. Gibson, B. W.; Cohen, P. Methods Enzymol. 1990, 193, 480-501.

13. Michel H.; Hunt, D. F.; Shabanowitz, J.; Bennett, J. J. Biol. Chem. 1988, 263, 1123-1130.

14. Erickson, A. K.; Payne, M.; Martino, P. A,; Rossomando, A. I.; Shabanowitz, J.; Weber, M. J.; Hunt, D. F.; Sturgill, T. W. J. Biol. Chem. 1990, 265, 19728-19735.

15. Alexander, J. E.; Hunt, D. F; Lee, M. K.; Shabanowitz, J.; Michel, H.; Berlin, S. C.; Macdonald, T. L.; Sundberg, R. J.;

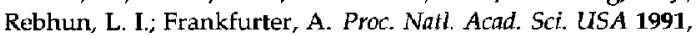
$88,4685-4689$.

16. Rossomando, A. J.; Wu, J.; Michael, H.; Shabanowitz, J.; Hunt, D. F.; Weber, M. J.; Sturgill, T. W. Proc. Nat. Acad. Sci. USA 1992, 89, 5779-5783.

17. Palczewski, K.; Buczylko, J.; I looser, P. V.; Carr, S. A.; I Iuddleston, M. J.; Crabb, J. W. I. Bio.. Chem. 1992, 267, 18991-18998.

18. Hou, J,; McKeehan, K,; Kan, M.; Carr, S. A.; Huddleston, M. J.; Crabb, J. W.; McKeehan, W. L. Protein Sct. 1993, 2, 86-92.

19. Fenselau, C.; Heller, D. N. Miller, M. S.; White, H. B. III Anal. Biochem 1985, 150, 309-314.

20. Poulter, L.; Ang, S.-G.; Gibson, B. W.; Williams, D. H.; Holmes, C. F. B.; Caudwell, F. B.; Pitcher, J.; Cohen, P. Eur. J. Biochem. 1988, 175, 497-510.

21. Schroeder, W.; Covey, T.; Hucho, F. FEBS Lett. 1990, 273, 31-35.

22. Labdon, J. E.; Nieves, D.; Schubart, U. K. I. Biol. Chem. 1992, $267,3506-3513$.

23. Covey, T.: Shushan, B.; Bonner, R.; Schröder, W.; Hucho F. In Methods in Protein Sequence Analysis; Jörnvall, H.; Höög, J. O.; Gustavsson, A. M., Eds.; Birkhäıser Press; Basel, 1991; pp. 249-256.

24. Huddleston, M. J.; Bean, M. F.; Carr, S. A. Anal. Chem. 1993, $65,877-884$.

25. Carr, S. A.; Huddleston, M. J.; Bean, M. F. Protein Sci., 1993, 2, 183-196.

26. Hemling, M. E.; Roberts, G. D.; Johnson, W.; Carr, S. A. Biomed. Environ. Mass Spectrom. 1990, 19, 677-691. 